\title{
Allogenic Mesenchymal Stem Cell Transplantation Ameliorates Nephritis in Lupus Mice Via Inhibition of B-Cell Activation
}

\author{
Xiaolei Ma,* Nan Che,* Zhifeng Gu,* Jing Huang,* Dandan Wang,* Jun Liang,* Yayi Hou,* \\ Gary Gilkeson, $\dagger$ Liwei Lu, $\neq$ and Lingyun Sun* \\ *Department of Immunology and Rheumatology, The Affiliated Drum Tower Hospital of Nanjing University \\ Medical School, Nanjing, China \\ $†$ Department of Rheumatology, Medical University of South Carolina, Charleston, SC, USA \\ $\ddagger$ Department of Pathology and Center of Infection and Immunology, The University of Hong Kong, Hong Kong, China
}

\begin{abstract}
Recent evidence indicates that bone marrow-derived mesenchymal stem cells (BM-MSCs) possess immunosuppressive properties both in vitro and in vivo. We have previously demonstrated that transplantation of human MSCs can significantly improve the autoimmune conditions in MRL/lpr mice. The current study aimed to determine the mechanisms by which murine BM-MSC transplantation (MSCT) ameliorates nephritis in MRL/lpr mice. In this study, we found that MSCT can significantly prolong the survival of MRL/lpr mice. Eight weeks after transplantation, MSCT-treated mice showed significantly smaller spleens than control animals, with fewer marginal zones (MZs), T1, T2, activated B-cells, and plasma cells. Moreover, serum levels of B-cell activating factor (BAFF) and IL-10 in MSCT-treated mice decreased significantly compared to those in the control group, while levels of serum TGF- $\beta$ were increased. Notably, decreased BAFF expression in both spleen and kidney was accompanied by decreased production of anti-dsDNA autoantibodies and proteinuria in MSCT-treated mice. Since BAFF is mainly expressed by T-cells and dendritic cells, we incubated BM-MSCs and DCs together and found that the production of BAFF by DCs was suppressed by MSCs. Thus, our findings suggest that MSCT may suppress the excessive activation of B-cells via inhibition of BAFF production in MRL/lpr mice.
\end{abstract}

Key words: Systemic lupus erythematosus; Mesenchymal stem cells; Transplantation; B-cell activating factor; B lymphocyte

\section{INTRODUCTION}

Systemic lupus erythematosus (SLE) is a multisystem autoimmune disorder resulting from generation of autoreactive antibodies to nuclear antigens by $\mathrm{B}$ lymphocytes, which modulates the T-cell repertoire through cytokine production and antigen presentation, leading to distant organ damage $(13,33)$. In addition, B-cells produce soluble mediators involved in the organization of lymphoid tissues and in the initiation and perpetuation of inflammatory processes $(4,23)$. So, B-cell hyperreactivity may play an important role in SLE pathogenesis. Some researchers have hypothesized that B-cell depletion might represent an effective treatment for SLE (25).

B-cell activating factor (BAFF) is a tumor necrosis factor (TNF) family cytokine that is essential for B-cell survival and maturation (27). It binds to three receptors, namely, transmembrane activator and calcium modulator ligand interactor (TACI), B-cell maturation antigen (BCMA), and BAFF receptor (BAFF-R) $(5,36)$. BAFF-transgenic (Tg) mice develop an autoimmune disease with hallmarks resembling human SLE, including autoantibodies against double-strand DNA (dsDNA), circulating immune complexes, and severe membranoproliferative glomerulonephritis (28). Elevated serum levels of BAFF were found in autoimmune diseases, including SLE and rheumatoid arthritis (28). Blockade of BAFF using soluble fusion proteins of BAFF receptors prevented autoimmunity in animal models of the disease $(15,34)$. Belimumab (Benlysta, Human Genome Sciences, Rockville, MD, USA) is a human G1- $\lambda$ monoclonal antibody that binds to soluble human BAFF and inhibits its biological activity $(1,16)$. It selectively reduces the numbers of cluster of differentiation 20-positive $\left(\mathrm{CD} 20^{+}\right)$B lymphocyte subsets, shortlived plasma cells, and anti-dsDNA antibody titers in

Received February 20, 2012; final acceptance October 16, 2012. Online prepub date: October 31, 2012.

Address correspondence to Lingyun Sun, M.D., Ph.D., Department of Immunology and Rheumatology, The Affiliated Drum Tower Hospital of Nanjing University Medical School, 321 Zhongshan Road, Nanjing, Jiangsu 210008, P. R. China. E-mail: lingyunsun2001@yahoo.com.cn or lingyunsun2012@163.com 
patients with SLE (42). A phase 3, randomized controlled trial (RCT) looking at 867 patients from 90 centers in 13 countries suggested that BAFF blockade, like belimumab, has the potential to be the first targeted biological treatment approved specifically for the treatment of SLE (29).

Bone marrow-derived mesenchymal stem cells (BMMSCs) are multipotent stem cells capable of differentiating into a variety of cell types including osteoblasts, chondrocytes, adipocytes, and myoblasts (12,32). In addition, MSCs can inhibit immune responses both in vitro and in vivo in a dose-dependent, non-human leukocyte antigen (HLA)-restricted manner $(8,9,17,18,20)$. These unique properties make MSCs attractive candidates for cell therapy for autoimmune disorders such as SLE. Up to now, our research center is the first unit engaged in MSCT for treatment of SLE. Our clinical trials have showed that patients improved with a marked decrease in the Systemic Lupus Erythematosus Disease Activity Index (SLEDAI) scores and anti-double-stranded DNA levels, although the mechanism is not so clear $(21,22,38-40,48)$. A previous report described MSC-mediated inhibition of human peripheral B-cell proliferation and differentiation into immunoglobulin-secreting cells (8), which suggests that B-cell might be a target of MSCs in the treatment of SLE.

In the present study, we sought to investigate the effect of BM-MSC transplantation on B-cell activation and BAFF expression and assessed the role of these effects in the amelioration of SLE in Murphy Roths Large-lymphoproliferation spontaneous mutation (MRL/ lpr) mice.

\section{MATERIALS AND METHODS}

\section{Mice}

Female MRL/Mp-lpr/lpr (MRL/lpr) mice and female Balb/c mice were purchased from Shanghai Laboratory Animal Center (Shanghai, China) and bred in our institution. The animal experiments were approved by the Ethics Committee for Animal Research of the Affiliated Drum Tower Hospital of Nanjing University Medical School. Female MRL/lpr mice were divided into three groups and treated with either intravenous injection of BM-MSCs derived from Balb/c (MSCT; $n=9$ ), BM nonadherent cells (treatment control; $n=9$ ), or saline (placebo; $n=11$ ) at 18 weeks of age. All cells were given at doses of $1 \times 10^{6}$ per mouse. The Balb/c mice $(n=9)$ were used as a control group and received no treatment. Mice were tested for proteinuria every 2 weeks with Coomassie Brilliant Blue (Tianjing Boyi Chemical Reagent, Co. Ltd., Tianjin, China). All mice were sacrificed at the age of 26 weeks (Fig. 1A).

\section{Cell Culture}

MSCs were obtained from Balb/c mice (female, 4-6 weeks of age). Bone marrow cells were harvested from femurs and tibias using the methods described by Dobson et al. (10) and were then cultivated in a plastic dish (Corning, Inc., Corning, NY, USA) according to the protocol for isolation and expansion of MSCs developed by Peister et al. (31). MSCs were then prepared for transplantation at a concentration of $2 \times 10^{6}$ cells $/ \mathrm{ml}$.

\section{$B$-Cell Isolation and Culture}

Mononuclear cells (MNCs) were isolated from the spleens of mice. Cell suspensions were treated with mouse B-cell-negative isolation kit, according to the instructions of the manufacturer (Miltenyi Biotec, Inc., Auburn, CA, USA). Negatively selected cells contained, on average, $96 \%$ B-cells, as assessed by flow cytometric analysis with a B220 monoclonal antibody. All cell cultures were performed in Roswell Park Memorial Institute (RPMI) 1640 medium (Gibco, Gaithersburg, MD, USA) supplemented with $10 \%$ fetal bovine serum (FBS; Gibco), $100 \mathrm{U} / \mathrm{ml}$ penicillin, and $100 \mu \mathrm{g} / \mathrm{ml}$ streptomycin (both Hyclone, Logan, UT, USA), in the absence or presence of the following stimuli: the cytosine-phosphate-guanine $(\mathrm{CpG})$ synthetic oligonucleotide $(2.5 \mu \mathrm{g} / \mathrm{ml}$; R\&D Systems, Minneapolis, MN, USA), recombinant cluster of differentiation 40 ligand (rCD40L, $100 \mathrm{ng} / \mathrm{ml}$; PeproTech, Rocky Hill, NJ, USA), goat anti-mouse IgG $(2 \mu \mathrm{g} / \mathrm{ml}$; Southern Biotech, Birmingham, AL, USA), interleukin-2 (IL-2, 50 U/ml; PeproTech), IL-4 (10 ng/ml; PeproTech), and IL-10 (10 ng/ml; PeproTech).

\section{Dendritic Cell Isolation and Culture}

Dendritic cells (DCs) were generated from bone marrow progenitor cells as previously described with some modifications (26). Briefly, bone marrow cells were isolated from tibiae and femurs of mice and were treated with red blood cell lysing buffer $\left[150 \mathrm{mM} \mathrm{NH}_{4} \mathrm{Cl}\right.$ (Beijing Chemical Reagent, Co. Ltd., Beijing, China), $10 \mathrm{mM} \mathrm{NaHCO}_{3}$ (Shanghai Lingfeng Chemical Reagent, Co. Ltd., Shanghai, China), and 0.4\% EDTA (Nanjing Sunshine Biotechnology, Co. Ltd., Nanjing, China)]. Cell density was adjusted to $1 \times 10^{6}$ cells with complete medium [RPMI 1640 supplemented with 10\% FBS, 100 $\mathrm{U} / \mathrm{ml}$ penicillin, $100 \mathrm{~g} / \mathrm{ml}$ streptomycin, $10 \mathrm{ng} / \mathrm{ml} \mathrm{recom-}$ binant granulocyte macrophage colony-stimulating factor (GM-CSF; R\&D Systems), and $1 \mathrm{ng} / \mathrm{ml}$ recombinant IL-4 (R\&D Systems)] and seeded into 12-well plates (Corning) at $2 \mathrm{ml} /$ well. All cultures were incubated at $37^{\circ} \mathrm{C}$ in $5 \%$ humidified $\mathrm{CO}_{2}$. Nonadherent granulocytes were removed after $48 \mathrm{~h}$ of culture and then fresh complete medium was added. Media were exchanged by half every $48 \mathrm{~h}$. After 6 days of culture, nonadherent and loosely adherent cells were harvested, and $>85 \%$ of the cells expressed characteristic DC-specific markers as determined by fluorescence-activated cell sorting (FACS). 
A

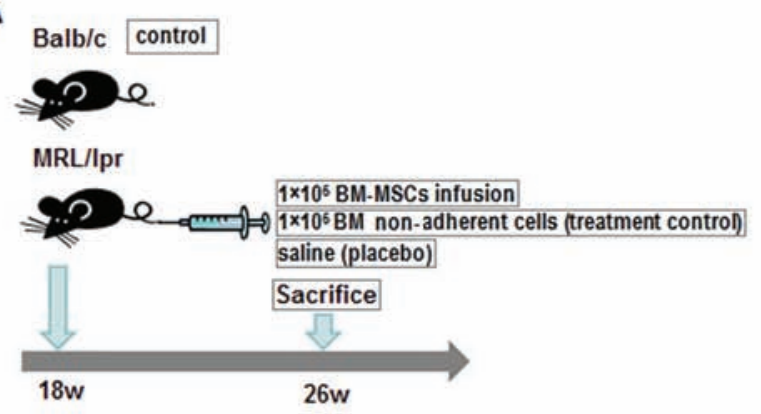

B

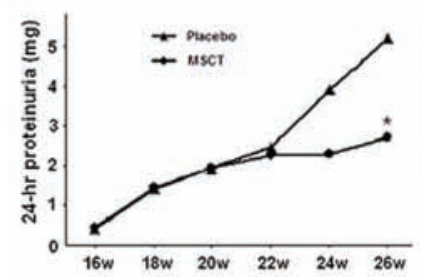

C

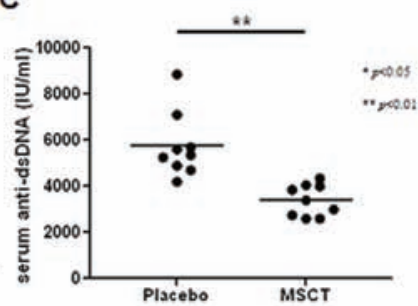

D
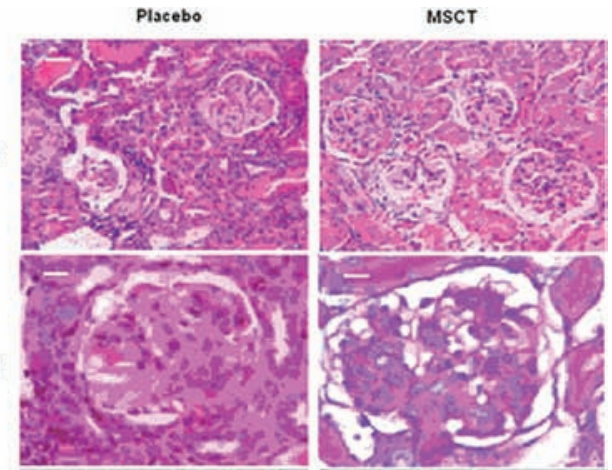

PAS $\times 600$
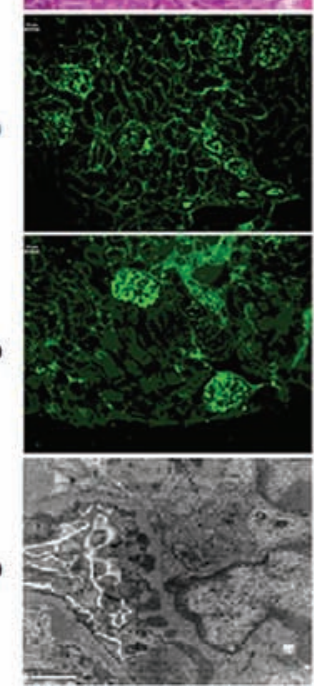

Ultrastructural $\times 8000$

Figure 1. Reduction of the 24-h proteinuria and serum anti-dsDNA antibody level of MRL/lpr mice. (A) Schema of bone marrow mesenchymal stem cell transplantation (MSCT) procedure. Bone marrow-derived mesenchymal stem cells (BM-MSCs; $n=9$ ), $1 \times 10^{6}$, BM nonadherent cells (treatment control) $(n=9)$, or saline (placebo) $(n=11)$ were infused into female Murphy Roths Largelymphoproliferation spontaneous mutation (MRL/lpr) mice through the tail vein. The Balb/c mice $(n=9)$ were used as a control group and received no treatment. Mice were tested for proteinuria every 2 weeks by Coomassie Brilliant Blue. All groups were sacrificed at 26 weeks for sample collection. (B) The 24-h proteinuria of mice in the placebo group increased gradually over the 18-week time frame. At 26 weeks, the 24-h proteinuria in the MSCT group $(2.71 \pm 0.78 \mathrm{mg})$ was significantly decreased compared to the placebo group $(5.21 \pm 1.18 \mathrm{mg})(p<0.01)$. (C) There was significant difference in anti-double-strand DNA (dsDNA) titers between the treatment and control groups at the age of 26 weeks. (D) MSCT reduced basal membrane disorder and mesangium cell overgrowth in glomerular (upper panels, H\&E staining, scale bar: $50 \mu \mathrm{m}$; upper second panels, PAS staining, scale bar: $50 \mu \mathrm{m}$ ). Immunohistochemistry showed that MSCT was able to diminish IgM and IgG deposition in glomerular of MRL/lpr mice (lower panels, scale bars: $20 \mu \mathrm{m}$ ). Electron-dense deposits in both mesangial and subepithelial areas were readily seen in kidneys of control groups (bottom, scale bars: $100 \mu \mathrm{m})$. Results are representative of three independent experiments. A probability of null hypothesis $<5 \%$ was considered statistically significant. $* p<0.05 ; * p<0.01$.

\section{Flow Cytometry}

The antibodies (Abs) used for flow cytometry were allophycocyanine (APC)-, fluorescein isothiocyanate (FITC)-, phycoerythrin (PE)-, or phycoerythrin-cyanine 5.5 (PE-Cy5.5)-conjugated anti-mouse B220, CD138, CD69, CD21, CD23, IgD, and IgM. All Abs described were purchased from eBioscience (San Diego, CA, USA) except for IgD, which was purchased from BD Pharmingen (San Diego, CA, USA). The cultured cells were collected, washed twice, and resuspended in $200 \mu \mathrm{l}$ of phosphate-buffered saline (PBS; Wuhan Boster Biological Technology, Co. Ltd., Wuhan, China) containing $0.1 \%$ bovine serum albumin (BSA; Sigma-Aldrich, St. Louis,
MO, USA). These cells were stained with specific labeled Abs or appropriate isotypic controls. The cells were incubated on ice for $30 \mathrm{~min}$, washed with PBS containing $0.1 \%$ BSA, and then fixed with a $1 \%$ paraformaldehyde (Xilong Chemical Reagent, Co. Ltd., Shantou, Guangdong, China) solution. Analyses were performed using FACScan and CellQuest software (BD Bioscience, San Jose, CA, USA).

\section{ELISA}

Quantitation of Serum Levels of Anti-dsDNA, BAFF, Interferon (IFN)- $\gamma$, IL-10, and Transforming Growth Factor $(T G F)-\beta$. Serum from treated and untreated mice was harvested and immediately frozen at $-80^{\circ} \mathrm{C}$ until 
its use. The concentration levels of anti-dsDNA, BAFF, IFN- $\gamma$, IL-10, and TGF- $\beta$ were measured by commercial kits according to the recommendations of the manufacturer (R\&D Systems, Minneapolis, MN, USA).

Quantitation of the Levels of $\operatorname{Ig} M, \operatorname{Ig} G$, and $\operatorname{IgA}$. We collected the supernatant from cell culture and immediately froze it at $-80^{\circ} \mathrm{C}$ until its use. The concentration levels of $\operatorname{IgM}, \operatorname{IgG}$, and $\operatorname{IgA}$ were measured by commercial kits according to the recommendations of the manufacturer (R\&D Systems).

\section{Histological Analysis of Mouse Kidneys and Spleens}

The kidneys and spleens were fixed in $10 \%$ formalin (Xilong Chemical Reagent, Co. Ltd.) for $24 \mathrm{~h}$ at $4^{\circ} \mathrm{C}$. Serial 5- $\mu \mathrm{m}$-thick kidney and spleen sections were mounted on glass slides coated with $10 \%$ poly-L-lysine (Nanjing Chemical Reagent, Co. Ltd., Nanjing, China). Paraffin sections $(4 \mu \mathrm{m})$ were stained with periodic acidSchiff (PAS; Nanjing Chemical Reagent, Co. Ltd.) and hematoxylin and eosin (H\&E; Nanjing Chemical Reagent, Co. Ltd.) reagents. Two kidneys of each group were prepared for transmission electron microscopy. The kidney was prefixed in $4 \%$ glutaraldehyde (Shanghai Lingfeng Chemical Reagent, Co. Ltd.) at $4{ }^{\circ} \mathrm{C}$ for $60 \mathrm{~min}$ and then it was washed with $0.1 \%$ sodium cacodylate buffer (pH 7.2-7.4; Nanjing Chemical Reagent, Co. Ltd.) four times for $15 \mathrm{~min}$ at $4^{\circ} \mathrm{C}$, stained with $1 \%$ osmic acid (Shanghai Shenbo Chemical Co. Ltd., Shanghai, China) for $2 \mathrm{~h}$, and poached in double distilled water for $10 \mathrm{~min}$. The samples, attached to grids, were dehydrated in ethanol and were dried. Ultrathin sections were cut using an ultramicrotome (Zhejiang Boyi Medical Equipment Factory, Zhejiang, China) and stained with both uranyl acetate (Nanjing Chemical Reagent, Co. Ltd.) and lead citrate (Shanghai No. 1 Chemical Reagent, Co. Ltd., Shanghai, China). Sections were observed under a JEM-1230 transmission electron microscope (Hitachi Ltd., Tokyo, Japan) at an accelerating voltage of $80 \mathrm{kV}$ by two pathologists who were blinded to the treatments.

Immunochemistry. Serial 5- $\mu$ m-thick kidney and spleen sections were mounted on glass slides coated with $10 \%$ poly-L-lysine. Sections were dewaxed in xylene and rehydrated in graded ethanols. Endogenous peroxidase activity was blocked by immersion in $0.3 \%$ methanolic peroxide (Shanghai Lingfeng Chemical Reagent, Co. Ltd.) for 30 min. Immunoreactivity was enhanced by microwave incubating the tissue sections for $10 \mathrm{~min}$ in $0.1 \mathrm{M}$ citrate buffer (Shanghai No. 1 Chemical Reagent, Co. Ltd.). Immunostaining was performed using the avidin-biotinperoxidase complex method with the antibodies for BAFF (1:200, Abcam, Cambridge, MA, USA), BCMA (1:200, Santa Cruz Biotechnologies, Dallas, TX, USA), TACI (1:200, Abcam), and BAFF-R (1:200, Abcam). Three independent pathologists evaluated the immunostaining. At least 10 high-power fields were randomly chosen, and at least 300 cells were counted. Images were captured using a digital CCD camera system connected to a Zeiss microscope (Zeiss, Thornwood, NY, USA).

Immunofluorescence. To detect immune complex deposits, cryostat sections $(4 \mu \mathrm{m})$ were fixed in chilled acetone (Nanjing Chemical Reagent, Co. Ltd.) and stained with an FITC-conjugated polyclonal goat anti-mouse IgG or IgM antibody (Organon Teknica, Scarborough, CA, USA). To detect the location of B-cells in the kidneys, cryostat sections $(4 \mu \mathrm{m})$ were fixed in chilled acetone and stained with an FITC-conjugated polyclonal goat antimouse B220 or CD138 antibody (eBioscience).

\section{Western Blotting}

The kidneys and spleens were lysed with lysis buffer (Invitrogen, Carlsbad, CA, USA). Equal amounts of protein were resolved by sodium dodecyl sulfate-polyacrylamide gel electrophoresis (SDS-PAGE; Nanjing Biosharp Technology, Co. Ltd., Nanjing, China) and transferred onto polyvinylidene difluoride (PVDF) membrane filters (Millipore Corporation, Billercia, MA, USA). The membranes were first blocked and then incubated with the primary antibodies (BAFF, 1:200; BCMA, 1:200; TACI, 1:200; BAFF-R, 1:200) described above, for $2 \mathrm{~h}$ at room temperature. Glyceraldehyde 3-phosphate dehydrogenase (GAPDH; 1:200; Cell Signaling Technology, Danvers, MA, USA) was used as a loading control. After three washes, filters were incubated with horseradish peroxidase-conjugated secondary antibodies (1:200, Santa Cruz) for $1 \mathrm{~h}$ at room temperature. Detection of immunocomplexes was performed with an enhanced chemiluminescence system (NEN Life Science Products, Boston, MA, USA).

\section{Statistical Analysis}

Quantitative data were expressed as the mean \pm SD. GraphPad Prism 4 software (Version 4.03; San Diego, CA, USA) was used for statistical analysis. Comparisons were performed using paired Student's $t$ test and Bonferroni correction. Values of $p<0.05$ are considered to be significant.

\section{RESULTS}

Treatment With MSCs Prolonged Survival and Ameliorated Lupus Nephritis in MRL/lpr Mice

Seven mice died in the treatment control group and two in the placebo group. On the other hand, all the mice in the MSCT group survived until sacrifice. Owing to the death of seven of the nine treatment control mice, this group is not reported here and reference to the controls refers to the untreated Balb/c mice. MSCT also significantly reduced $24-\mathrm{h}$ proteinuria (Fig. 1B) and serum 
levels of anti-dsDNA antibody (Fig. 1C). At 26 weeks, the 24-h proteinuria in the MSCT group was significantly lower $(2.71 \pm 1.78 \mathrm{mg})$ than in the placebo group $(5.21 \pm 2.18 \mathrm{mg})(p<0.05)$. The serum level of antidsDNA was significantly reduced in the MSCT mice $(3,415 \pm 681 \mathrm{IU} / \mathrm{ml})$ compared with that in the placebo $(5,752 \pm 1,425 \mathrm{IU} / \mathrm{ml})(p<0.01)$.

Histological examination of kidneys of placebo mice at 26 weeks showed typical glomerulonephritis, characterized by enlarged glomeruli, proliferation of glomerular cells, infiltrating inflammatory cells, increased mesangial matrix, and crescent formation (Fig. 1D). In contrast, MSCT-treated mice showed a marked reduction of glomerulonephritis, varying degrees of focal glomerular cell proliferation, occasional inflammatory cells, and only a slight increase in mesangial matrix.

Immunofluorescence staining of the kidneys in the placebo group showed IgM and IgG deposited extensively under the mesangium, in the subepithelium and subendothelium. In the MSCT group, IgM and IgG deposition significantly decreased. The presence of immune complexes was further confirmed by electron microscopic analysis. Electron-dense deposits in both mesangial and subepithelial areas were readily seen in kidneys of control groups.

\section{Treatment With MSCs Downregulates the Maturation and Differentiation of B-Cells of MRL/pr Mice}

Since we found reduced antibody production after MSCT, we further looked for changes in the population of mature B-cells in the spleens of placebo or MSCTtreated lupus mice. As shown in Figure 2, treatment with MSCT resulted in a significant reduction in the number of spleen cells (Fig. 2A) and in the B220+ (Fig. 2B) cell counts. Figure $2 \mathrm{C}$ and $\mathrm{D}$ demonstrates the percentage and absolute numbers of mature $\left(\operatorname{IgM}^{+} \operatorname{IgD}{ }^{+}\right)$B-cells out of the total B-cell population. Figure $2 \mathrm{E}$ shows representative dot plots of the latter. The percentage of $\operatorname{IgM}^{+} \operatorname{IgD}{ }^{+}$B-cells was significantly reduced in MSCT-treated mice, as was the number of $\operatorname{IgM}^{+} \operatorname{IgD}^{+}$cells. The percentage and absolute numbers of plasma cells seems to be decreased in the MSCT group, but there was no statistical significance (data not shown).

We further tested the effect of treatment with BMMSCs on the B-cell intermediate differentiation stages defined as T1 $\left(\mathrm{B} 220^{+} \mathrm{CD} 23^{-} \mathrm{CD} 21^{-} \mathrm{IgM}^{\mathrm{high}}\right)$ and T2 $\left(\mathrm{B} 220^{+}\right.$ $\left.\mathrm{CD} 23^{+} \mathrm{CD} 21^{\text {high }} \mathrm{IgM} \mathrm{M}^{\text {high }}\right)$. Figure $2 \mathrm{~F}-\mathrm{J}$ presents the percentages and absolute numbers of B-cells at the T1 and T2 stages in the different experimental groups. The percentages of T1 cells out of the a total of B220 cells diminished significantly $(7.26 \pm 4.02 \% \mathrm{~T} 1$ and $4.84 \pm 2.67 \% \mathrm{~T} 2$ in the placebo groups vs. $3.43 \pm 2.07 \% \mathrm{~T} 1$ and $2.56 \pm 1.39 \%$ T2 in MSCT mice), following transplantation of BMMSCs (Fig. 2F and H). Similar results are shown for the total numbers of T1 and T2 cells $\left(5.09 \pm 2.00 \times 10^{6} \mathrm{~T} 1\right.$ and $3.68 \pm 1.73 \times 10^{6} \mathrm{~T} 2$ in the placebo groups versus $2.71 \pm$ $1.71 \times 10^{6} \mathrm{~T} 1$ and $1.95 \pm 1.19 \times 10^{6} \mathrm{~T} 2$ in MSCT mice) (Fig. 2G and I). Figure $2 \mathrm{~J}$ shows representative dot plots of the latter. Thus, MSCT downregulates the maturation and differentiation of B-cells in MRL/lpr mice, which are generally elevated in lupus.

\section{BM-MSCs Inhibit B-Cell Activation and Immunoglobulin Production In Vitro}

We next investigated the effects of BM-MSCs on B-cell activation and stimulation with $\mathrm{CpG}, \mathrm{rCD} 40 \mathrm{~L}$, antiimmunoglobulin antibodies, IL-2, and IL-4. Inhibition of B-cell activation by the percentage of $\mathrm{B} 220^{+} \mathrm{CD} 69^{+}$ cells was observed at the $\mathrm{B}$-cell/BM-MSC ratio of $1: 1$ $(p<0.03)$ (Fig. 3A). This effect was also detectable by supernatant from BM-MSCs cultured with B-cells.

Purified B-cells were next incubated with or without BM-MSCs at 1:1 and 1:5 ratios in the presence of $\mathrm{CpG}$, CD40L, anti-immunoglobulin, IL-2, IL-4, and IL-10. BM-MSCs inhibited the production of $\operatorname{IgM}, \operatorname{IgG}$, and $\operatorname{IgA}$ at a B-cell/MSC ratio of 1:1 ( $p<0.01$ for $\operatorname{IgM}, p<0.05$ for $\operatorname{IgG}, p<0.05$ for IgA), as assessed by ELISA (Fig. 3B). No inhibition of immunoglobulin production was observed at 1:5 B-cell/MSC ratio (data not shown).

Treatment With MSCs Downregulates the Expression of Serum BAFF in MRL/pr Mice, While BM-MSCs Reduce the Production of BAFF by Suppressing DCs In Vitro

Since the expression of BAFF was reported to be elevated in patients with SLE and in lupus mouse models $(38,44)$, it was of interest to determine the effect of treatment with MSCT on BAFF secretion. As shown in Figure 4A, MSCT significantly inhibited the secretion of BAFF (control $-4.23 \pm 1.82 \mathrm{ng} / \mathrm{ml}$, placebo $-46.99 \pm 12.57 \mathrm{ng} / \mathrm{ml}$, MSCT $-24.78 \pm 18.71 \mathrm{ng} / \mathrm{ml})$. Since IFN- $\gamma$ and IL-10 are pathogenic cytokines in SLE and are reported to activate BAFF (5), we tested whether the reduction in BAFF was associated with a diminished secretion of those cytokines. As shown in Figure 4B and C, MSCT significantly inhibited the secretion of IL-10 (control $-4.06 \pm 3.58 \mathrm{pg} / \mathrm{ml}$, placebo-46.07 $\pm 17.63 \mathrm{pg} / \mathrm{ml}, \mathrm{MSCT}-18.94 \pm 7.05 \mathrm{pg} / \mathrm{ml}$ ). The levels of IFN- $\gamma$ were also downregulated, but with no statistical significance. Meanwhile, the immunosuppressive cytokine TGF- $\beta$ in serum was upregulated by MSCT (Fig. 4D) (control $-11.14 \pm 5.57 \mathrm{ng} / \mathrm{ml}$, placebo $-2.43 \pm 0.92 \mathrm{ng} / \mathrm{ml}$, MSCT $-3.58 \pm 1.22 \mathrm{ng} / \mathrm{ml})$. Thus, the downregulated production of BAFF following transplantation of BM-MSCs might be, at least partially, due to the diminished secretion of IL-10 and increased secretion of TGF- $\beta$.

Since BAFF is mainly expressed by T-cells and dendritic cells, we next incubated BM-MSCs and DCs together. Purified DCs were stimulated with $\mathrm{CpG}$ for 24 h (DC'), 

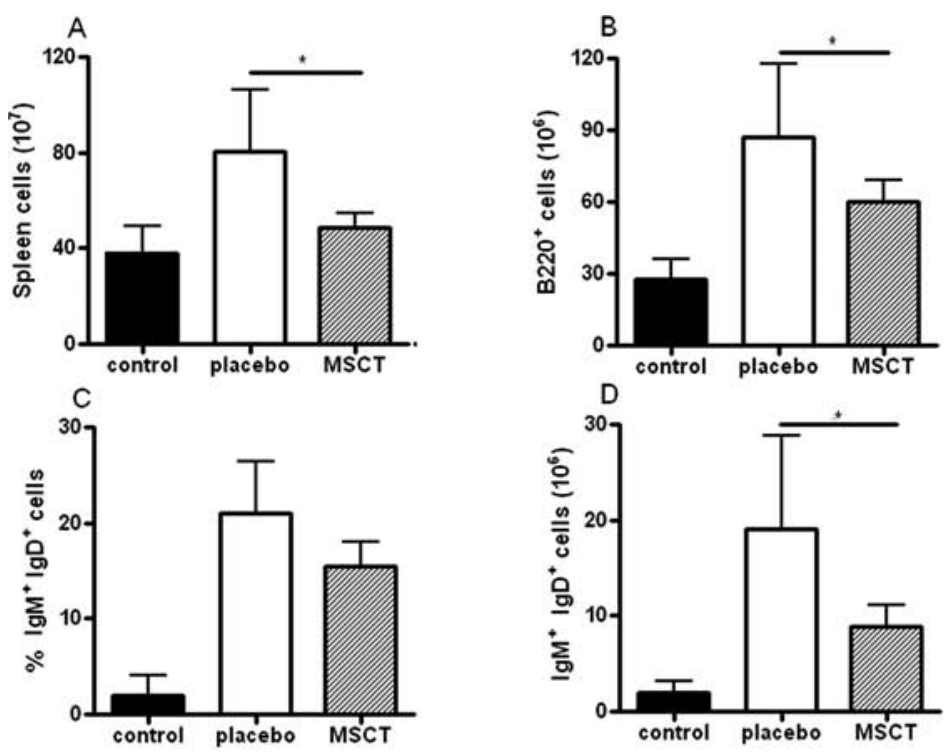

E
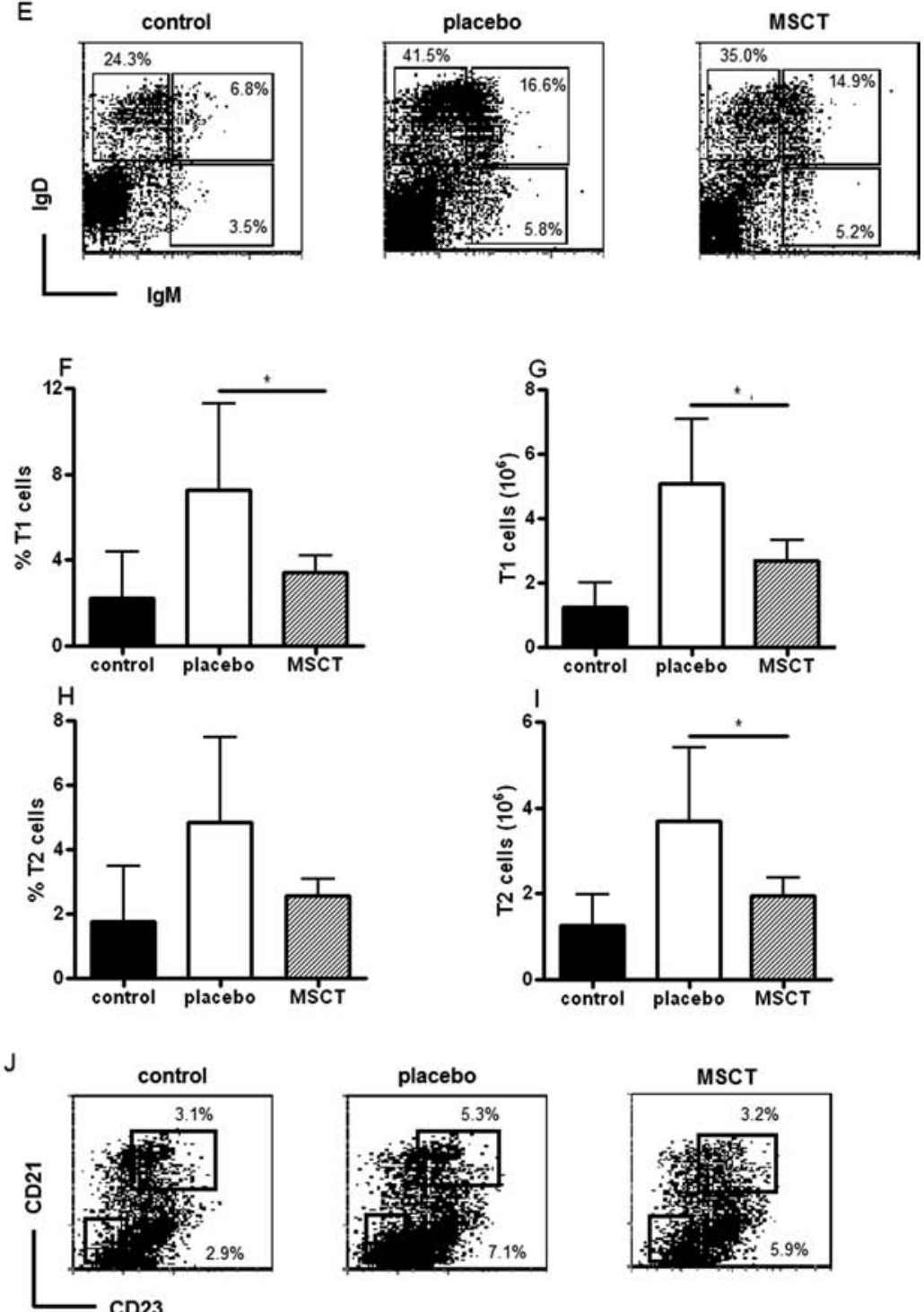


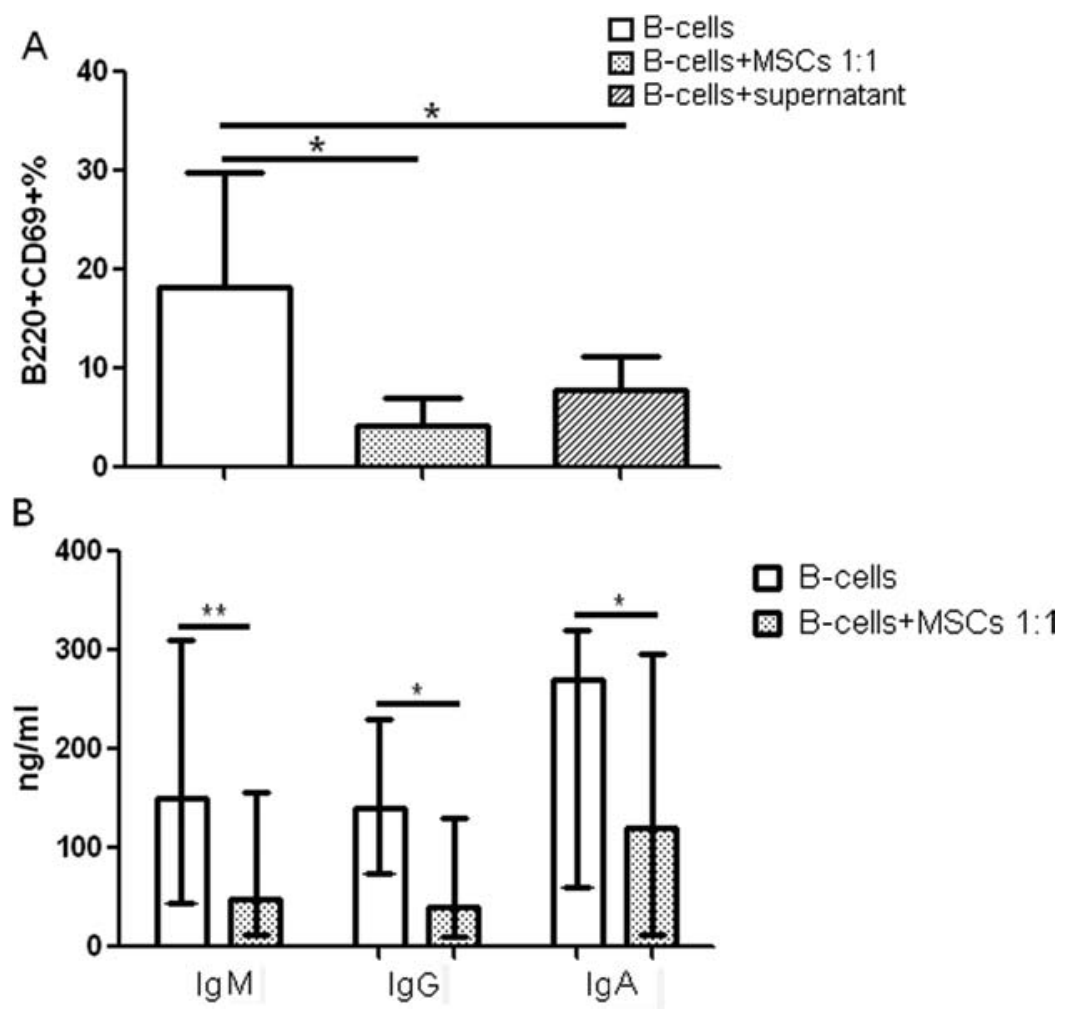

Figure 3. BM-MSCs inhibit B-cell activation and immunoglobulin production in vitro. (A) B-cells purified from the spleens of MRL/ lpr mice were cocultured for 3 days with allogeneic BM-MSC suspensions at 1:1 ratios or supernatant from BM-MSCs cultured in the presence of cytosine-phosphate-guanine $(\mathrm{CpG})$, recombinant cluster of differentiation 40 ligand (rCD40L), anti-IgG antibodies, interleukin (IL)-2, and IL-4. Maximum and minimum values of B-cells (B220 CD69+) from five independent experiments are shown. $* p<0.05$. (B) Purified B-cells were incubated for 7 days with or without BM-MSCs at a 1:1 ratio in the presence of CpG, rCD40L, anti-IgG antibodies, IL-2, IL-4, and IL-10. The secretion of IgM, IgG, IgA was evaluated by ELISA. Maximum and minimum values from five independent experiments are shown. ${ }^{*} p<0.05$. ${ }^{*} p<0.01$.

were next incubated with BM-MSCs at 1:1 and 1:10 ratios or incubated with BM-MSCs for 3 days, and were next stimulated with $\mathrm{CpG}$ for $24 \mathrm{~h}$. Inhibition of BAFF production was observed at all the conditions tested (Fig. 4E).

\section{MSCs Inhibit BAFF Secretion Levels and Its Receptors in the Spleens and Kidneys of MRL/lpr Mice}

Next, we examined the levels of BAFF and its receptors in kidneys and spleens of mice treated with placebo or MSCs. Immunohistochemical examination of kidney sections revealed that positive staining of BAFF and its receptors was mainly located in the glomerular mesangium, renal interstitium, and the renal tubule inflammatory cell infiltrate. Positive staining in the renal tubule was located on the edges and lumens of the tubules in the placebo group (Fig. 5A). In the MSCT group, expression of BAFF and its receptor was much lower than in the placebo group (Fig. 5A, B). Immunoblotting analysis showed similar expression patterns of BAFF and its receptors in kidneys and spleens (Fig. 5C).

\section{DISCUSSION}

SLE is a systemic autoimmune disease characterized by continuous generation of autoantibody-producing cells. It is well established that B-cells are critical in the pathogenesis of the disease through autoantibody-dependent

FACING PAGE

Figure 2. B-cell maturation and differentiation are downregulated in MSCT mice. Spleen cells of mice were harvested following treatment experiments and were stained with antibodies to B220, IgM, IgD, cluster of differentiation 21 (CD21), and CD23. Means of total spleen cell counts (A), B220 cell counts (B), percentage of $\mathrm{IgM}^{+} \mathrm{IgD}^{+} \mathrm{B}$-cells out of the total B-cell population $(\mathrm{C})$, absolute numbers of $\operatorname{IgM}^{+} \operatorname{IgD}{ }^{+}$B-cells (D), representative dot plots of $\operatorname{IgM}^{+} \operatorname{IgD}^{+}$B-cell staining (E) of five independent experiments. Mean percentages (F) and numbers $(\mathrm{G})$ of $\mathrm{T} 1\left(\mathrm{~B} 220^{+} \mathrm{CD} 23^{-} \mathrm{CD} 21^{-} \mathrm{IgM}^{\text {high }}\right) \mathrm{B}$-cells out of the total B-cell population of five experiments. Mean percentages $(\mathrm{H})$ and numbers $(\mathrm{I})$ of $\mathrm{T} 2\left(\mathrm{~B} 220^{+} \mathrm{CD} 23^{+} \mathrm{CD} 21^{\text {high }} \operatorname{IgM} \mathrm{M}^{\text {high }}\right) \mathrm{B}$-cells and $(\mathrm{J})$ representative dot plots of $\mathrm{CD} 21$ and $\mathrm{CD} 23$ on gated $\mathrm{B} 220^{+} \mathrm{IgM}^{\text {high }}$ cells of five experiments. A probability of null hypothesis $<5 \%$ was considered statistically significant. ${ }^{*} p \leq 0.05$. 

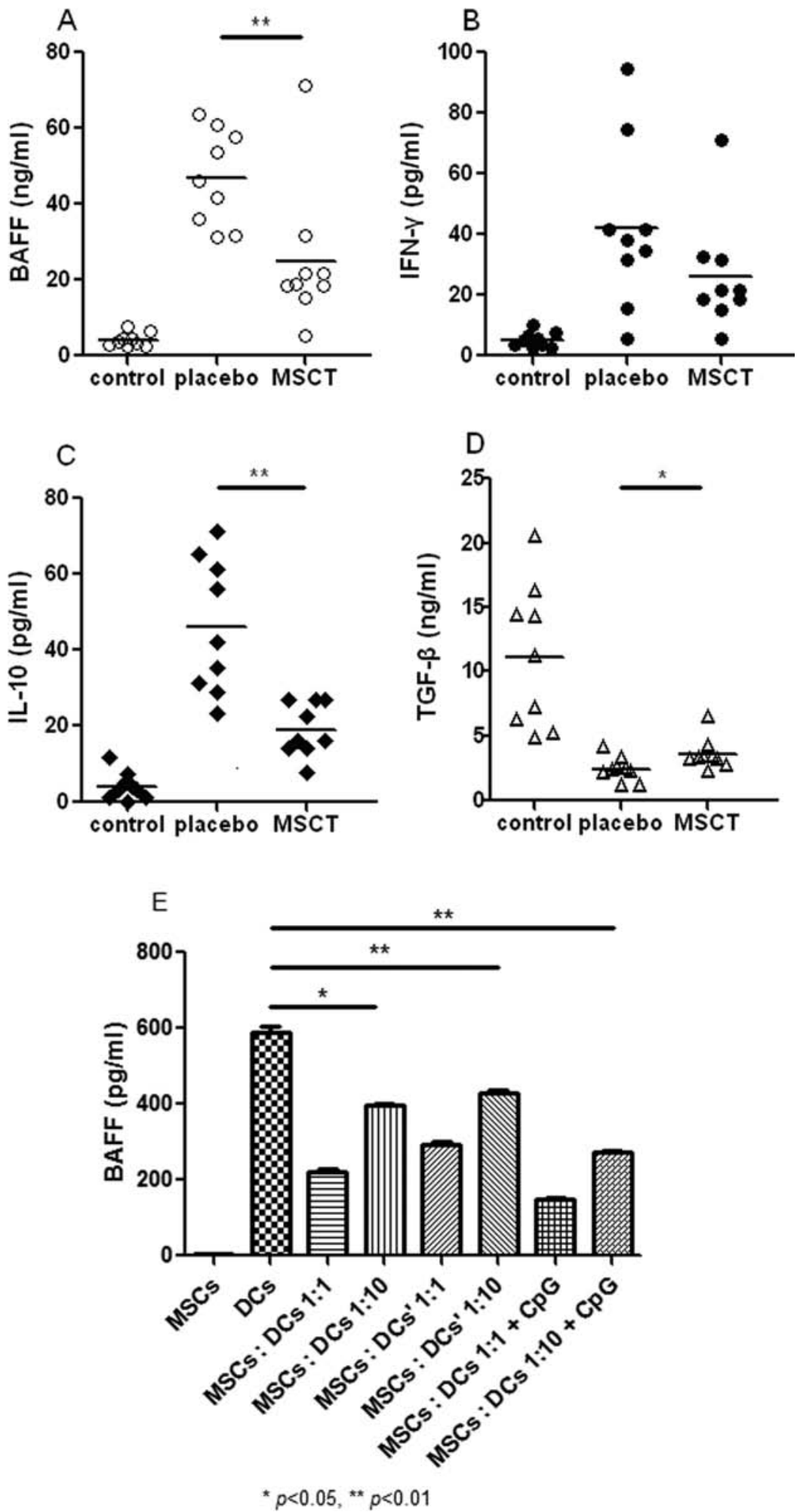

Figure 4. The effect of treatment with MSCT on the expression of B-cell activating factor (BAFF) and interferon (IFN)- $\gamma$, interleukin-10 (IL-10), and transforming growth factor (TGF)- $\beta$ secretion. (A) Mean secretion of BAFF in serum measured by ELISA. (B) Mean secretion of interferon IFN- $\gamma$ in serum measured by ELISA. (C) Mean secretion of IL-10 in serum measured by ELISA. (D) Mean secretion of TGF- $\beta$ in serum measured by ELISA. (E) The inhibition of BAFF production at the BM-MSCs/dendritic cells (DCs) ratio of 1:1 and 1:10. DCs': Purified DCs stimulated with CpG for $24 \mathrm{~h}$ before BM-MSC exposure. Results are representative of three independent experiments. A probability of null hypothesis $<5 \%$ was considered statistically significant. $* p<0.05$. $* * p<0.01$. 


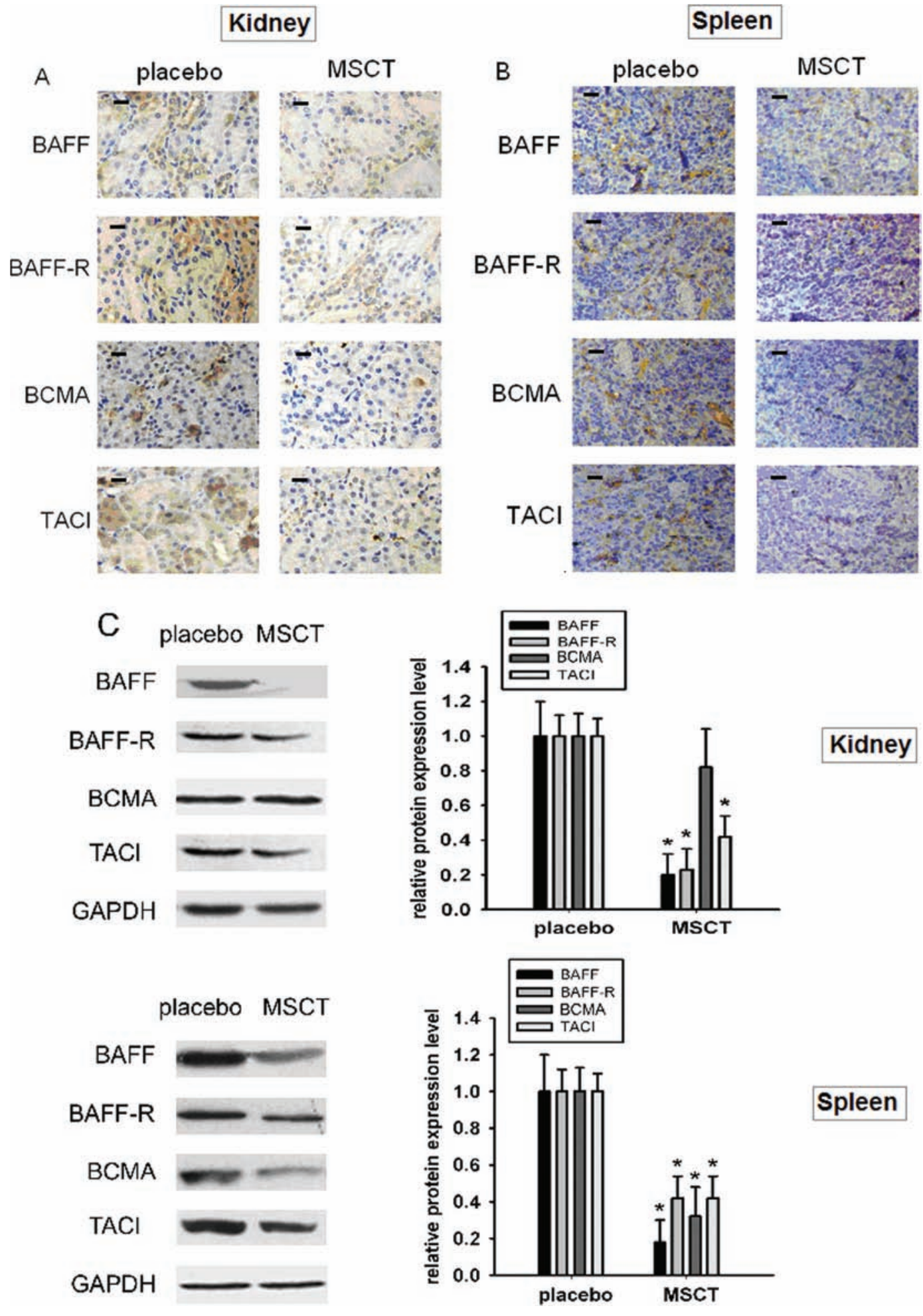

Figure 5. The expression of BAFF, BAFF-R, BCMA, and TACI in spleens and kidneys. (A) Expression of BAFF and its receptors [BAFF-R, B-cell maturation antigen (BCMA) and transmembrane activator and calcium modulator ligand interactor (TACI)] in the kidneys of MRL/lpr mice treated with placebo or MSCT were detected by immunohistochemistry (scale bars: $20 \mu \mathrm{m}$ ). (B) Expression of BAFF and its receptors in the spleens of MRL/lpr mice treated with placebo or MSCT were detected by immunohistochemistry (scale bars: $20 \mu \mathrm{m}$ ). (C) Western blots of BAFF and its receptor expression in kidneys and spleens (representative of three experiments performed). A probability of null hypothesis $<5 \%$ was considered statistically significant. GAPDH: glyceraldehyde 3-phosphate dehydrogenase. ${ }^{*} p<0.05$. 
and -independent mechanisms. We have shown that the transplantation of allogeneic BM-MSCs could inhibit the maturation and differentiation of B-cells of MRL/lpr mice, especially the mature $\left(\operatorname{IgM}^{+} \operatorname{IgD}{ }^{+}\right)$and transitional (T1 and T2) B-cell populations. BM-MSCs also inhibited the activation and immunoglobulin production in vitro.

BAFF overproduction was reported to be associated with autoimmune and lymphoproliferative disorders such as SLE $(7,45)$, rheumatoid arthritis (7), Sjogren's syndrome (14), and multiple myeloma (30). In SLE patients, as in lupus-prone mouse models, BAFF serum levels and gene expression were reported to be significantly higher than in healthy controls $(7,15,34,47)$. In normal mice, the exogenous addition of BAFF enhanced the antibody responses to antigen challenge, whereas treatments that blocked BAFF inhibited those responses $(2,35,41)$. In the present study, we found that transplantation of BM-MSCs, which ameliorated serological and clinical manifestations of SLE in spontaneous and induced mouse models $(38,40,48)$, significantly reduced the serum levels and expression of BAFF in kidneys and spleens (Figs. 4 and 5). The effect of MSCT was specific since the injection of saline did not significantly affect the expression and secretion of BAFF. In agreement, the blocking of BAFF in animal models of autoimmune diseases (arthritis, spontaneous B lymphocyte autoimmunity, and SLE) reduced autoantibody production and disease manifestations $(19,24,43)$.

Reports on the effects of BAFF in Tg mice indicate that BAFF induces T1, T2, and marginal zone (MZ) B-cells in the periphery and that, in BAFF-deficient mice, the maturation of B-cells is inhibited (28). Moreover, BAFF was reported to regulate B-cell survival (11). In our study, we observed a significant and specific reduction in the mature $\left(\operatorname{Ig} \mathrm{M}^{+} \operatorname{IgD}{ }^{+}\right)$and transitional (T1 and T2) B-cell populations in spleens of MSCT mice (Fig. 2). It is likely that the reduced $\mathrm{BAFF}$ levels following transplantation of BM-MSCs led to the decrease in transitional and mature B-cell populations. The reduction in T1 B-cells, which were shown to be not affected by BAFF (35), is probably due to the additional effects of MSCT that are distinct from BAFF blockade.

Both IFN- $\gamma$ and IL-10, two pathogenic cytokines in SLE, were reported to stimulate BAFF expression by activating macrophages, monocytes, and dendritic cells (26). On the other hand, TGF- $\beta$, an immunosuppressive cytokine, is downregulated in lupus (37). In this study, we detected a significant and specific reduction in IL-10 secretion in MSCT mice. The secretion of IFN- $\gamma$ was also decreased in MSCT mice. The secretion of TGF- $\beta$ was upregulated in the MSCT groups compared with the placebo or treatment control. Thus, it is possible that the downregulated IL-10 and upregulated TGF- $\beta$ played a role in diminishing the levels of BAFF. Since dendritic cells are considered the main producers of BAFF (2), we incubated BM-MSCs and DCs together to see whether MSCs could inhibit the production of BAFF. We found that the production of BAFF by DCs can be suppressed by MSCs. Therefore, we think that the MSCs may modulate B-cell populations through its effects on BAFF. This may be one of the ways that the MSCs indirectly inhibit B-cell function.

In this study, we showed that BM-MSCs inhibit in vitro B-cell activation and immunoglobulin production. B-cells isolated from the spleen of mice were stimulated with $\mathrm{CpG}$, rCD40L, anti-immunoglobulin antibodies, IL-2, and IL-4. Such a cocktail provides an optimal trigger for most B-cell effector functions (3), thus, allowing investigation of the direct effects of BM-MSCs on B-cell activities. Following culture with BM-MSCs, B-cell activation and immunoglobulin production were significantly impaired. In our previous studies, we found that the effects of umbilical cord MSCs on B-cells appeared to be strongly influenced by the relative in vitro concentrations, as suggested by a gradual loss of inhibition observed at lower MSC/B-cell ratios. MSCs markedly suppressed B-cell differentiation as shown by the decreased number of CD138 $8^{+}$cells and reduced levels of $\mathrm{IgM}$ and $\mathrm{IgG}$ production in coculture. As revealed by transwell experiments, soluble factors produced by MSCs might be involved in mediating B-cell suppression. The maximum inhibition effect was observed at the MSC/B-cell ratio of 1:1. This inhibitory effect was still detectable at a 1:10 ratio of $\mathrm{MSC} / \mathrm{B}$-cell and diminished at 1:100 ratios (6). T-cell activation is strongly inhibited by MSCs even at low concentrations of MSCs (46), so we cannot exclude that their in vivo effect on B-cells may be stronger when T-cell help is required. Although we and others have observed that MSCs could induce T-cell apoptosis, in the present study, we did not observe significant B-cell apoptosis. We noted that previous studies showed that B-cell proliferation was inhibited by MSCs through an arrest in the $\mathrm{G}_{0} / \mathrm{G}_{1}$ phase of the cell cycle and not through the induction of apoptosis (8). Another study found that MSC and its supernatant inhibit B lymphocyte proliferation with the mechanism correlated with the MSC concentration and the MSC-secreted cytokines, but MSCs do not induce B lymphocyte apoptosis in vitro (44).

In conclusion, the findings of this study provide a new basis for the rationalization of the therapeutic effect of BM-MSC transplantation. Indeed, this study demonstrated that the mechanisms of action by which MSCT suppresses hyperreactive B-cells involve BAFF at multiple levels. Transplantation of BM-MSCs downregulates the expression and secretion of IFN- $\gamma$ and IL-10 and upregulates the levels of TGF- $\beta$, leading to reduced levels of serum and peripheral BAFF expression. Reduction of BAFF downregulates $\mathrm{T} 1, \mathrm{~T} 2$, and mature $\mathrm{B}$-cell populations and then plays a role in disease progression. Reduction of maturation and differentiation of B-cells results in diminishing 
levels of serum autoantibodies and 24-h proteinuria, reducing renal damage. In short, in addition to the prominent inhibitory effects on T-cells, MSCT may modulate B-cell populations through its effects on BAFF.

ACKNOWLEDGMENTS: The authors thank Dr. Ha HX, Dr. Guo YQ, and Dr. Zhai HS (all members of the Department of Immunology and Rheumatology, The Affiliated Drum Tower Hospital of Nanjing University Medical School, Nanjing, China) for their care of the animals and the Hou Yayi Laboratory FACS Facility for their assistance in cell sorting. This work was supported by the Major International (Regional) Joint Research Project (No. 81120108021), National Natural Science Foundation of China (No. 30972736), Jiangsu Province Natural Science Foundation (BK2009034), Jiangsu Province 'Six Summit Talent' Foundation, Jiangsu Kejiao Xingwei Program, and Nanjing Public Health Bureau Youth Startup Project (QYK11165). Xiaolei Ma and Lingyun Sun developed the concept and design for the study. Liwei Lu, Yayi Hou, and Gary Gilkeson designed and supervised the experiments. Xiaolei $M a$, Nan Che, Zhifeng Gu, and Jing Huang provided animal samples and animal data. Xiaolei Ma, Zhifeng Gu, Nan Che, Jing Huang, and Dandan Wang performed the experiments and analyzed the data. Xiaolei Ma, Jun Liang, and Jing Huang performed statistical analysis. Zhifeng Gu, Xiaolei Ma, Nan Che, and Jing Huang performed molecular modeling and analysis. Xiaolei Ma and Lingyun Sun wrote the manuscript. All authors commented on the manuscript. The authors declare no conflict of interest.

\section{REFERENCES}

1. Baker, K. P.; Edwards, B. M.; Main, S. H.; Choi, G. H.; Wager, R. E.; Halpern, W. G.; Lappin, P. B.; Riccobene, T.; Abramian, D.; Sekut, L.; Sturm, B.; Poortman, C.; Minter, R. R.; Dobson, C. L.; Williams, E.; Carmen, S.; Smith, R.; Roschke, V.; Hilbert, D. M.; Vaughan, T. J.; Albert, V. R. Generation and characterization of LymphoStat-B, a human monoclonal antibody that antagonizes the bioactivities of B lymphocyte stimulator. Arthritis Rheum. 48:3253-3265; 2003.

2. Batten, M.; Groom, J.; Cachero, T. G.; Qian, F.; Schneider, P.; Tschopp, J.; Browning, J. L.; Mackay, F. BAFF mediates survival of peripheral immature B lymphocytes. J. Exp. Med. 192:1453-1466; 2000.

3. Bernasconi, N. L.; Onai, N.; Lanzavecchia, A. A role for Tolllike receptors in acquired immunity: Up-regulation of TLR9 by BCR triggering in naive $\mathrm{B}$ cells and constitutive expression in memory B cells. Blood 101:4500-4504; 2003.

4. Browning, J. L. B cells move to centre stage: Novel opportunities for autoimmune disease treatment. Nat. Rev. Drug Discov. 5:564-576; 2006.

5. Carter, R. H.; Zhao, H.; Liu, X.; Pelletier, M.; Chatham, W.; Kimberly, R.; Zhou, T. Expression and occupancy of BAFF-R on B cells in systemic lupus erythematosus. Arthritis Rheum. 52:3943-3954; 2005.

6. Che, N.; Li, X.; Zhou, S.; Liu, R.; Shi, D.; Lu, L.; Sun, L. Umbilical cord mesenchymal stem cells suppress B-cell proliferation and differentiation. Cell. Immunol. 274:46-53; 2012.

7. Cheema, G. S.; Roschke, V.; Hilbert, D. M.; Stohl, W. Elevated serum B lymphocyte stimulator levels in patients with systemic immune-based rheumatic diseases. Arthritis Rheum. 44:1313-1319; 2001.
8. Corcione,A.; Benvenuto, F.; Ferretti, E.; Giunti,D.; Cappiello, V.; Cazzanti, F.; Risso, M.; Gualandi, F.; Mancardi, G. L.; Pistoia, V.; Uccelli, A. Human mesenchymal stem cells modulate B-cell functions. Blood 107:367-372; 2006.

9. Di Nicola, M.; Carlo-Stella, C.; Magni, M.; Milanesi, M.; Longoni, P. D.; Matteucci, P.; Grisanti, S.; Gianni, A. M. Human bone marrow stromal cells suppress T-lymphocyte proliferation induced by cellular or nonspecific mitogenic stimuli. Blood 99:3838-3843; 2002.

10. Dobson, K. R.; Reading, L.; Haberey, M.; Marine, X.; Scutt, A. Centrifugal isolation of bone marrow from bone: An improved method for the recovery and quantitation of bone marrow osteoprogenitor cells from rat tibiae and femurae. Calcif. Tissue Int. 65:411-413; 1999.

11. Enzler, T.; Bonizzi, G.; Silverman, G. J.; Otero, D. C.; Widhopf, G. F.; Anzelon-Mills, A.; Rickert, R. C.; Karin, M. Alternative and classical NF-kappa B signaling retain autoreactive $\mathrm{B}$ cells in the splenic marginal zone and result in lupus-like disease. Immunity 25:403-415; 2006.

12. Friedenstein, A. J.; Chailakhyan, R. K.; Latsinik, N. V.; Panasyuk, A. F.; Keiliss-Borok, I. V. Stromal cells responsible for transferring the microenvironment of the hemopoietic tissues. Cloning in vitro and retransplantation in vivo. Transplantation 17:331-340; 1974.

13. Grammer, A. C.; Lipsky, P. E. B cell abnormalities in systemic lupus erythematosus. Arthritis Res. Ther. 5:S22-S27; 2003.

14. Groom, J.; Kalled, S. L.; Cutler, A. H.; Olson, C.; Woodcock, S. A.; Schneider, P.; Tschopp, J.; Cachero, T. G.; Batten, M.; Wheway, J.; Mauri, D.; Cavill, D.; Gordon, T. P.; Mackay, C. R.; Mackay, F. Association of BAFF/BLyS overexpression and altered B cell differentiation with Sjögren's syndrome. J. Clin. Invest. 109:59-68; 2002.

15. Gross, J. A.; Johnston, J.; Mudri, S.; Enselman, R.; Dillon, S. R.; Madden, K.; Xu, W.; Parrish-Novak, J.; Foster, D.; Lofton-Day, C.; Moore, M.; Littau, A.; Grossman, A.; Haugen, H.; Foley, K.; Blumberg, H.; Harrison, K.; Kindsvogel, W.; Clegg, C. H. TACI and BCMA are receptors for a TNF homologue implicated in B-cell autoimmune disease. Nature 404:995-999; 2000.

16. Halpern, W. G.; Lappin, P.; Zanardi, T.; Cai, W.; Corcoran, M.; Zhong, J.; Baker, K. P. Chronic administration of belimumab, a BLyS antagonist, decreases tissue and peripheral blood B-lymphocyte populations in cynomolgus monkeys: Pharmacokinetic, pharmacodynamic, and toxicologic effects. Toxicol. Sci. 91:586-599; 2006.

17. Klyushnenkova, E.; Mosca, J. D.; Zernetkina, V.; Majumdar, M. K.; Beggs, K. J.; Simonetti, D. W.; Deans, R. J.; McIntosh, K. R. T cell responses to allogeneic human mesenchymal stem cells: Immunogenicity, tolerance, and suppression. J. Biomed. Sci. 12:47-57; 2005.

18. Krampera, M.; Glennie, S.; Dyson, J.; Scott, D.; Laylor, R.; Simpson, E.; Dazzi, F. Bone marrow mesenchymal stem cells inhibit the response of naive and memory antigenspecific T cells to their cognate peptide. Blood 101:37223729; 2003.

19. Lai Kwan Lam, Q.; King Hung Ko, O.; Zheng, B. J.; Lu, L. Local BAFF gene silencing suppresses Th17-cell generation and ameliorates autoimmune arthritis. Proc. Natl. Acad. Sci. USA 105:14993-14998; 2008.

20. Le Blanc, K. Immunomodulatory effects of fetal and adult mesenchymal stem cells. Cytotherapy 5:485-489; 2003.

21. Liang, J.; Gu, F.; Wang, H.; Hua, B.; Hou, Y.; Shi, S.; Lu, L.; Sun, L. Mesenchymal stem cell transplantation for 
diffuse alveolar hemorrhage in SLE. Nat. Rev. Rheumatol. 6:486-489; 2010.

22. Liang, J.; Zhang, H.; Hua, B.; Wang, H.; Lu, L.; Shi, S.; Hou, Y.; Zeng, X.; Gilkeson, G. S.; Sun, L. Allogenic mesenchymal stem cells transplantation in refractory systemic lupus erythematosus: A pilot clinical study. Ann. Rheum. Dis. 69:1423-1429; 2010.

23. Lipsky, P. E. Systemic lupus erythematosus: An autoimmune disease of B cell hyperactivity. Nat. Immunol. 2:764766; 2001.

24. Liu, W.; Szalai, A.; Zhao, L.; Liu, D.; Martin, F.; Kimberly, R. P.; Zhou, T.; Carter, R. H. Control of spontaneous B lymphocyte autoimmunity with adenovirus-encoded soluble TACI. Arthritis Rheum. 50:1884-1896; 2004.

25. Looney, R. J.; Anolik, J. H.; Campbell, D.; Felgar, R. E.; Young, F.; Arend, L. J.; Sloand, J. A.; Rosenblatt, J.; Sanz, I. $B$ cell depletion as a novel treatment for systemic lupus erythematosus: A phase I/II dose-escalation trial of rituximab. Arthritis Rheum. 50:2580-2589; 2004.

26. Mackay, F.; Browning, J. L. BAFF: A fundamental survival factor for B cells. Nat. Rev. Immunol. 2:465-475; 2002.

27. Mackay, F.; Schneider, P.; Rennert, P.; Browning, J. BAFF AND APRIL: A tutorial on B cell survival. Annu. Rev. Immunol. 21:231-264; 2003.

28. Mackay, F.; Woodcock, S. A.; Lawton, P.; Ambrose, C.; Baetscher, M.; Schneider, P.; Tschopp, J.; Browning, J. L. Mice transgenic for BAFF develop lymphocytic disorders along with autoimmune manifestations. J. Exp. Med. 190:1697-1710; 1999.

29. Navarra, S. V.; Guzmán, R. M.; Gallacher, A. E.; Hall, S.; Levy, R. A.; Jimenez, R. E.; Li, E. K.; Thomas, M.; Kim, H. Y.; León, M. G.; Tanasescu, C.; Nasonov, E.; Lan, J. L.; Pineda, L.; Zhong, Z. J.; Freimuth, W.; Petri, M. A.; BLISS-52 Study Group. Efficacy and safety of belimumab in patients with active systemic lupus erythematosus: A randomised, placebo-controlled, phase 3 trial. Lancet 377:721-731; 2011.

30. Novak, A. J.; Darce, J. R.; Arendt, B. K.; Harder, B.; Henderson, K.; Kindsvogel, W.; Gross, J. A.; Greipp, P. R.; Jelinek, D. F. Expression of BCMA, TACI, and BAFF-R in multiple myeloma: A mechanism for growth and survival. Blood 103:689-694; 2004.

31. Peister, A.; Mellad, J. A.; Larson, B. L.; Hall, B. M.; Gibson, L. F.; Prockop, D. J. Adult stem cells from bone marrow (MSCs) isolated from different strains of inbred mice vary in surface epitopes, rates of proliferation, and differentiation potential. Blood 103:1662-1668; 2004.

32. Prockop, D. J. Marrow stromal cells as stem cells for nonhematopoietic tissues. Science 276:71-74; 1997.

33. Rahman, A.; Isenberg, D. A. Systemic lupus erythematosus. N. Engl. J. Med. 358:929-939; 2008.

34. Ramanujam, M.; Wang, X.; Huang, W.; Schiffer, L.; Grimaldi, C.; Akkerman, A.; Diamond, B.; Madaio, M. P.; Davidson, A. Mechanism of action of transmembrane activator and calcium modulator ligand interactor-Ig in murine systemic lupus erythematosus. J. Immunol. 173:3524-3534; 2004.

35. Schiemann, B.; Gommerman, J. L.; Vora, K.; Cachero, T. G.; Shulga-Morskaya, S.; Dobles, M.; Frew, E.; Scott, M. L. An essential role for BAFF in the normal development of B cells through a BCMA-independent pathway. Science 293:2111-2114; 2001.

36. Schneider, P.; Mackay, F.; Steiner, V.; Hofmann, K.; Bodmer, J. L.; Holler, N.; Ambrose, C.; Lawton, P.; Bixler, S.; Acha-Orbea, H.; Valmori, D.; Romero, P.; Werner-Favre,
C.; Zubler, R. H.; Browning, J. L.; Tschopp, J. BAFF, a novel ligand of the tumor necrosis factor family, stimulates B cell growth. J. Exp. Med. 189:1747-1756; 1999.

37. Sthoeger, Z. M.; Sharabi, A.; Dayan, M.; Zinger, H.; Asher, I.; Sela, U.; Mozes, E. The tolerogenic peptide, hCDR1, down-regulates pathogenic cytokines and apoptosis and up-regulates immunosuppressive molecules and regulatory $\mathrm{T}$ cells in peripheral blood mononuclear cells of lupus patients. Hum. Immunol. 70:139-145; 2009.

38. Sun, L.; Akiyama, K.; Zhang, H.; Yamaza, T.; Hou Y.; Zhao, S.; Xu, T.; Le, A.; Shi, S. Mesenchymal stem cell transplantation reverses multiorgan dysfunction in systemic lupus erythematosus mice and humans. Stem Cells 27:1421-1432; 2009.

39. Sun, L.; Wang, D.; Liang, J.; Zhang, H.; Feng, X.; Wang, H.; Hua, B.; Liu, B.; Ye, S.; Hu, X.; Xu, W.; Zeng, X.; Hou, Y.; Gilkeson, G. S.; Silver, R. M.; Lu, L.; Shi, S. Umbilical cord mesenchymal stem cell transplantation in severe and refractory systemic lupus erythematosus. Arthritis Rheum. 62:2467-2475; 2010.

40. Sun, L.; Zhang, H.; Feng, X. Mesenchymal stem cells transplantation for refractory systemic lupus erythematosus. Arthritis Rheum. 58:S925; 2008.

41. Thompson, J. S.; Schneider, P.; Kalled, S. L.; Wang, L.; Lefevre, E. A.; Cachero, T. G.; MacKay, F.; Bixler, S. A.; Zafari, M.; Liu, Z. Y.; Woodcock, S. A.; Qian, F.; Batten, M.; Madry, C.; Richard, Y.; Benjamin, C. D.; Browning, J. L.; Tsapis, A.; Tschopp, J.; Ambrose, C. BAFF binds to the tumor necrosis factor receptor-like molecule B cell maturation antigen and is important for maintaining the peripheral B cell population. J. Exp. Med. 192:129-135; 2000.

42. Wallace, D. J.; Stohl, W.; Furie, R. A.; Lisse, J. R.; McKay, J. D.; Merrill, J. T.; Petri, M. A.; Ginzler, E. M.; Chatham, W. W.; McCune, W. J.; Fernandez, V.; Chevrier, M. R.; Zhong, Z. J.; Freimuth, W. W. A phase II, randomized, double-blind, placebo-controlled, dose-ranging study of belimumab in patients with active systemic lupus erythematosus. Arthritis Rheum. 61:1168-1178; 2009.

43. Wang, H.; Marsters, S. A.; Baker, T.; Chan, B.; Lee, W. P.; Fu, L.; Tumas, D.; Yan, M.; Dixit, V. M.; Ashkenazi, A.; Grewal, I. S. TACI-ligand interactions are required for T cell activation and collagen-induced arthritis in mice. Nat. Immunol. 2:632-637; 2001.

44. Wu, L. Q.; Bai, H.; Wang, C. B.; Yang, X. L.; Zhao, Q.; Yang, Y. W.; Lin, M. Effects of mesenchymal stem cells on proliferation and apoptosis of allogeneic B lymphocytes. Zhonghua Yi Xue Za Zhi 88:2562-2565; 2008.

45. Xu, S.; Lam, K. P. B-cell maturation protein, which binds the tumor necrosis factor family members BAFF and APRIL, is dispensable for humoral immune responses. Mol. Cell Biol. 21:4067-4074; 2001.

46. Zappia, E.; Casazza, S.; Pedemonte, E.; Benvenuto, F.; Bonanni, I.; Gerdoni, E.; Giunti, D.; Ceravolo, A.; Cazzanti, F.; Frassoni, F.; Mancardi, G.; Uccelli, A. Mesenchymal stem cells ameliorate experimental autoimmune encephalomyelitis inducing T-cell anergy. Blood 106:1755-1761; 2005.

47. Zhang, J.; Roschke, V.; Baker, K. P.; Wang, Z.; Alarcón, G. S.; Fessler, B. J.; Bastian, H.; Kimberly, R. P.; Zhou, T. Cutting edge: A role for B lymphocyte stimulator in systemic lupus erythematosus. J. Immunol. 166:6-10; 2001.

48. Zhou, K.; Zhang, H.; Jin, O.; Feng, X.; Yao, G.; Hou, Y.; Sun, L. Transplantation of human bone marrow mesenchymal stem cell ameliorates the autoimmune pathogenesis in MRL/lpr mice. Cell. Mol. Immunol. 5:417-424; 2008. 